\title{
Using Petri Nets in the analysis of sequential automata models with direct applications on the transport systems with accumulation areas
}

\author{
Dan Ungureanu-Anghel \\ Dep. of Automation and Applied Informatics, \\ "Politehnica" University of Timisoara \\ Faculty of Automation and Computers
}

\section{Introduction}

The development of flexible manufacturing systems (FMS) led implicitly to the revaluation of place and significance of the transport systems. A FMS cannot be considered efficient if the afferent transport system is not itself an efficient one. In these circumstances, the importance of the transport system had risen, from the classical phase, in which this had a role preponderant to transport the pieces from one machine to another, to a phase in which the tasks of the transport system were extended (automatic sorting, the automatic selection of the destination for a piece, computing and choosing the optimal route, etc.), talking now about intelligent transport systems.

Transport systems with accumulation area (TSAA) belongs to the class of intelligent transport systems, being capable, based on some algorithms or on some functioning specifications (static - determined during design, or dynamic - which can be modified during the operation depending on the operator demands) to execute transfers of pieces or other transport elements (trolleys), according to the requirements. TSAA founds applicability in the most diverse places: automated warehouses, flexible fabrication lines, sorting systems, etc.

In specialized literature the field of industrial transport systems was not neglected. However, the majority of the authors approach these fields from the prospect of the analysis of the materials flux and of the allocated transport time (Chiang et.al 2008)(Ge et. al. 2008)(Polic\&Jezernik 2008).

Other approaches related to transport systems can be found in the papers that deals with either the road or rail system (Li et al 2008) (Giua \& Seatzu 2008).

The approach of industrial transport systems, within this chapter, it is done different from the way of approach existing in literature, once by direct concentration on a certain type of transport system (TSAA), and the second is done not by the analysis of the materials flux, but by the analysis the mode of administration at the lowest level of materials transport. Starting from the base structure of the TSAA it was identified a basic mechanical structure, called node, for which it was elaborated the adequate model of automatic type. After the 
validation of this model, following the structural and behaviour analysis, it passed to the obtaining of generic models.

The higher complexity of these systems, make almost impossible the modelling based on differential equations, which led to the TSAA approach as a discrete event systems (DES).

For the modelling of the constitutive elements of TSAA, and of TSAA on the whole, considered as DES, there will be used models of untimed deterministic automatic type. Because of the fact that the structural and behaviour analysis of the larger models of automatic type is difficult, as well as the lack of dedicated tools, it led to the use of one methodology less common, but which has a very high efficiency. The used method of approach is based on the conversion of the models of automatic type in models of untimed labelled Petri Net type, the structural and behaviour analysis being made using the PetriNets Toolbox from Matlab.

In order that the obtained results from the analysis of the model of Petri Net type to be applicable (in fact to validate) to the model of automatic type it is necessary to fulfil the following condition: a model of Petri Net type obtained from a model of automatic type need to have the topology of state machine type. Only if this condition is complete satisfied the results can validate entirely the model of automatic type. This compulsoriness is imposed especially by the construction manner of the models of automatic type, respectively Petri Nets. Models of automatic type are based on the propagation of the model topology, while the models of Petri Net type are based on the propagation of the markings.

Within this chapter, is pursued the creation of a unified procedural and methodological background, for the conjunction between the models of untimed deterministic automatic type and the untimed label Petri Nets type with direct applications on the transport systems with the accumulation areas.

For the beginning, within the chapter is done a presentation of the theoretical aspects of the connections between the models of automatic type and the models of Petri Nets type connected to: theoretical notions concerning the relation between the models of automatic type and the models of Petri Nets type; the algorithm used for the conversion of the models of automatic type in models of Petri Net type; the validation conditions of the obtained results through the analysis of the models of Petri Net type equivalent to the basic models of automatic type.

Having as a base the theoretical considerations, the approach of the TSAA field is done in the first phase through a general presentation of TSAA and of their basic structures, continuing with the modelling of the constitutive elements of TSAA with the help of the models of automatic type, starting from the basic structure and ending with generic models. The structural and behaviour analysis of the established models of automatic type is realized by their conversion in models of untimed Petri Net type, on these models is being made the structural and behaviour analysis.

Some conclusions are presented at the end of the chapter.

\section{Theoretical considerations connected to the models of automatic type, respectively Petri Nets}

Both modelling methods, automata respectively Petri Nets, have at the base the using of states and transitions for the description of a system, it results that between them are similarities and differences (Cassandras \& Lafortune 2001). 
Modelling with automata respectively Petri Nets, as well as the model type choosing it is left to the modeller latitude (Murata 1989).

In this way, if it is desired the modelling of a DES only based on its external events, without having an interest in an explicit way on the hidden activities, and then a model of automatic type is satisfactory. If instead is desired a refinement of the internal operations then a model of Petri Net type is more favourable (Cassandras \& Lafortune 2001) (Pastravanu 1997).

For the model of automatic type it was considered that these are of deterministic type. A deterministic automata is defined as follows:

Definition 1. Untimed deterministic automata (Cassandras $\mathcal{E}$ Lafortune 2001)

A deterministic automata, marked by $G$, is a sextuple

$$
G=\left(X, E, \delta, \Gamma, x_{0}\right)
$$

where:

- $\quad X$ is the set of states;

- $\quad \sum$ is a finite set of events associated with the transitions from G;

- $\delta: X \times \sum \rightarrow X$ is the transition function: $\delta(x, e)=y$, means the appearance of a transition labelled through the event $\mathrm{e}$ in the state $x$, which has as a result the transition in the state $\mathrm{y}$; in general, $\delta$ is a partial function on his domain of definition.

- $\quad \Gamma: X \rightarrow 2^{E}$ is the active event function; $\Gamma(x)$ is the set of all events e for which $\delta(x, e)$ is defined and is called by the active event from $G$ accordingly to the active state $x$.

- $x_{0}$ is the initial state of the system.

For the model of Petri Net type it was considered that these are of labelled type and untimed. An untimed labelled Petri Net is defined as follows.

Definition 2. Labelled Petri Net (Cassandras E Lafortune 2001)

A labelled Petri Net is a weighted graph

$$
P N=\left(P, T, F, W, \Sigma, l, M_{0}\right)
$$

(net topology), where:

- $P$ represents the finite multitude of positions, with $P=\left\{p_{1}, p_{2}, p_{3}, \ldots, p_{n}\right\}$;

- $T$ represents the finite multitude of transitions, with $T=\left\{t_{1}, t_{2}, t_{3}, \ldots, t_{m}\right\}$;

- $F \subseteq(P \times T) \cup(T \times P)$ represents the multitude of arcs from the positions to transitions and from transitions to positions, each arc being represented by $\left(p_{i}, t_{j}\right)$, respectively $\left(\mathrm{t}_{\mathrm{j}}, \mathrm{p}_{\mathrm{i}}\right)$, where $i, j \in N$;

- $W: A \rightarrow\{1,2,3 \ldots\}$ represents the balanced function of arcs;

- $\sum$ represents the set of events for the transitions labels;

- $l: T \rightarrow \sum$ represents the labelled transition function;

- $M_{0} \in N^{n}$ represents the initial marking of the net.

As it was mentioned earlier, the automatons and the Petri Nets operate with states and transitions. In this way are possible transformations of the models of automatic type in models of Petri Net type and vice versa. The subject of synthesis of the models from one 
way of representation in the other one is presented in detail in literature.(Pastravanu 1997)(Cortadella et al 1995)(Cortadella et al 1998)(Hellgren et al 2001)(Cassez \& Roux 2004).. The algorithm used for the conversion of untimed deterministic automata $G=\left(X, \sum, \delta, \Gamma, x_{0}, X_{m}\right)$, into an untimed Petri Net $P N=\left(P, T, F, W, M_{0}\right)$ is:

Step 1. The determination of the multitude of positions $P$

Each state from $\mathrm{X}$ is transformed into an equivalent position in $P$.

$$
\forall x_{i} \in X: x_{i} \rightarrow p_{i}, p_{i} \in P
$$

which means that the multitude $P$ has exactly so much elements that are in the multitude $X$. Step 2. The determination of the transitions multitude $\mathrm{T}$ For each pair of states from $X$, designated by $\left(x, x^{\prime}\right)$, with

$$
x^{\prime}=\delta(x, e), \quad e \in \Gamma(x)
$$

it has associated a transition labelled $t_{i} \in T$, in the Petri Net.

In the end result the multitude:

$$
T=\bigcup\left\{t:\left(x, x^{\prime}\right), x, x^{\prime} \in X, x^{\prime}=\delta(x, e), e \in \Gamma(x)\right\}
$$

Step 3. The determination of the arc multitude $\mathrm{F}$

It is attached the arcs $(p, t),\left(t, p^{\prime}\right) \in F$ all having the weight $1, w(p, t)=1, w\left(t, p^{\prime}\right)=1$ if exists the correspondence $\left(x, x^{\prime}\right) \rightarrow\left(p, p^{\prime}\right)$

With other words:

$$
\text { if }\left(x, x^{\prime}\right) \rightarrow\left(p, p^{\prime}\right): x^{\prime}=\delta(x, e), e \in \Gamma(x) \text { then } \exists(p, t) \text { and }\left(t, p^{\prime}\right) p, p^{\prime} \in P, t \in T
$$

In the end, result the multitude:

$$
F=\{(p, t): p \in P, t \in T\} \bigcup\left\{\left(t, p^{\prime}\right): p^{\prime} \in P, t \in T\right\}
$$

and

$$
W: F \rightarrow\{1\}
$$

Step 4. The determination of the event multitude $\sum$

The set of events is obtained as being:

$$
\sum=E
$$

Step 5. The determination of transition functions $l$. The label attached to the transition is the event $e$ which led to change of the state $x$ in $x^{\prime}$. 
For the transition $t \in T:(p, t),\left(t, p^{\prime}\right) \in F \quad$ the event and function 1 and associated label are defined as:

$$
l(t)=e, e \in \sum \text { and } x^{\prime}=\delta(x, e)
$$

Step 6. The determination of initial marking $M_{0}$

The initial marking $M_{0}$ is assigned accordingly to the initial state $x_{0}$.

The way of using the conversion algorithm from the model of untimed deterministic automatic type in the model of untimed labelled Petri Net type is exemplified through the next example.

Example . It is considered the untimed deterministic automata from figure 1.

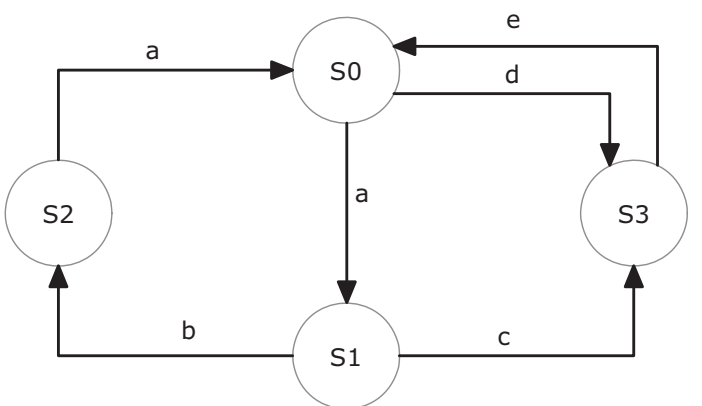

Fig. 1. The structure of the considered untimed deterministic automata

The considered automata formalized mathematical by: $A S=\left(X, E, \delta, \Gamma, x_{0}\right)$ where:

- The multitude of states: $X=\left\{S_{0}, S_{1}, S_{2}, S_{3}\right\}$

- The multitude of events: $E=\{a, b, c, d, e\}$

- The multitude of possible events and the transition functions of the states:

\begin{tabular}{|c|l|}
\hline$\Gamma\left(S_{0}\right)=\{a, d\}$ & $\delta\left(S_{0}, a\right)=S_{1}$ \\
& $\delta\left(S_{0}, d\right)=S_{3}$ \\
\hline$\Gamma\left(S_{1}\right)=\{b, c\}$ & $\delta\left(S_{1}, b\right)=S_{2}$ \\
& $\delta\left(S_{1}, c\right)=S_{3}$ \\
\hline$\Gamma\left(S_{2}\right)=\{a\}$ & $\delta\left(S_{2}, a\right)=S_{0}$ \\
\hline$\Gamma\left(S_{3}\right)=\{e\}$ & $\delta\left(S_{3}, e\right)=S_{0}$ \\
\hline
\end{tabular}

- $\quad$ The initial state: $x_{0}=S_{0}$.

For obtaining the equivalent untimed labelled Petri Net is applied the presented algorithm:

Step 1. The determination of multitude of positions $\mathrm{P}$ :

$$
S_{i} \rightarrow p_{i} ; i=\overline{0,3}
$$

from where results that $P=\left\{p_{0}, p_{1}, p_{2}, p_{3}\right\}$ 
Step 2. The determination of multitude of transitions T:

\begin{tabular}{|c|c|c|c|}
\hline State & $\begin{array}{c}\text { States } \\
\text { connection }\end{array}$ & $\begin{array}{c}\text { The transition } \\
\text { function }\end{array}$ & $\begin{array}{c}\text { The associated } \\
\text { transition }\end{array}$ \\
\hline$S_{0}$ & $\left(S_{0}, S_{1}\right)$ & $\delta\left(S_{0}, a\right)=S_{1}$ & $t_{1}$ \\
\hline & $\left(S_{0}, S_{3}\right)$ & $\delta\left(S_{0}, d\right)=S_{3}$ & $t_{2}$ \\
\hline$S_{1}$ & $\left(S_{1}, S_{2}\right)$ & $\delta\left(S_{1}, b\right)=S_{2}$ & $t_{3}$ \\
\hline & $\left(S_{1}, S_{3}\right)$ & $\delta\left(S_{1}, c\right)=S_{3}$ & $t_{4}$ \\
\hline$S_{2}$ & $\left(S_{2}, S_{0}\right)$ & $\delta\left(S_{2}, a\right)=S_{0}$ & $t_{5}$ \\
\hline$S_{3}$ & $\left(S_{3}, S_{0}\right)$ & $\delta\left(S_{3}, e\right)=S_{0}$ & $t_{6}$ \\
\hline
\end{tabular}

From where results that $T=\left\{t_{1}, t_{2}, t_{3}, t_{4}, t_{5}, t_{6}\right\}$

Step 3. The determination of multitude of $\operatorname{arcs} \mathrm{F}$ and of their shares

\begin{tabular}{|c|c|c|c|}
\hline Transition & $\begin{array}{c}\text { States } \\
\text { connection }\end{array}$ & $\begin{array}{c}\text { The connection of } \\
\text { equivalent positions }\end{array}$ & Arcs \\
\hline$t_{1}$ & $\left(S_{0}, S_{1}\right)$ & $\left(p_{0}, p_{1}\right)$ & $\left(p_{0}, t_{1}\right),\left(t_{1}, p_{1}\right)$ \\
\hline$t_{2}$ & $\left(S_{0}, S_{3}\right)$ & $\left(p_{0}, p_{3}\right)$ & $\left(p_{0}, t_{2}\right),\left(t_{2}, p_{3}\right)$ \\
\hline$t_{3}$ & $\left(S_{1}, S_{2}\right)$ & $\left(p_{2}, p_{3}\right)$ & $\left(p_{1}, t_{3}\right),\left(t_{3}, p_{2}\right)$ \\
\hline$t_{4}$ & $\left(S_{1}, S_{3}\right)$ & $\left(p_{2}, p_{4}\right)$ & $\left(p_{1}, t_{4}\right),\left(t_{4}, p_{3}\right)$ \\
\hline$t_{5}$ & $\left(S_{2}, S_{0}\right)$ & $\left(p_{3}, p_{1}\right)$ & $\left(p_{2}, t_{5}\right),\left(t_{5}, p_{0}\right)$ \\
\hline$t_{6}$ & $\left(S_{3}, S_{0}\right)$ & $\left(p_{4}, p_{0}\right)$ & $\left(p_{3}, t_{6}\right),\left(t_{6}, p_{0}\right)$ \\
\hline
\end{tabular}

From where results that

$$
F=\left\{\left(p_{1}, t_{1}\right),\left(p_{1}, t_{2}\right),\left(p_{2}, t_{3}\right),\left(p_{2}, t_{4}\right),\left(p_{3}, t_{5}\right),\left(p_{4}, t_{6}\right)\right\} \bigcup
$$

$$
\left\{\left(t_{1}, p_{2}\right),\left(t_{2}, p_{4}\right),\left(t_{3}, p_{3}\right),\left(t_{4}, p_{4}\right),\left(t_{5}, p_{1}\right),\left(t_{6}, p_{1}\right)\right.
$$

The multitude of arcs shares:

$$
\begin{gathered}
W=\left\{w\left(p_{1}, t_{1}\right)=1, w\left(p_{1}, t_{2}\right)=1, w\left(p_{2}, t_{3}\right)=1, w\left(p_{2}, t_{4}\right)=1, w\left(p_{3}, t_{5}\right)=1, w\left(p_{4}, t_{6}\right)=1,\right. \\
\left.w\left(t_{1}, p_{2}\right)=1, w\left(t_{2}, p_{4}\right)=1, w\left(t_{3}, p_{3}\right)=1, w\left(t_{4}, p_{4}\right)=1, w\left(t_{5}, p_{1}\right)=1, w\left(t_{6}, p_{1}\right)=1\right\}
\end{gathered}
$$

Step 4 . The determination of multitude of events $\Sigma$

$$
\sum=\{a, b, c, d, e\}
$$

Step 5 . The determination of transition functions $l$ 


\begin{tabular}{|c|c|c|}
\hline Transition & Connected arcs & $\begin{array}{c}\text { Associated } \\
\text { events }\end{array}$ \\
\hline$t_{1}$ & $\left(p_{1}, t_{1}\right),\left(t_{1}, p_{2}\right)$ & $a$ \\
\hline$t_{2}$ & $\left(p_{1}, t_{2}\right),\left(t_{2}, p_{4}\right)$ & $d$ \\
\hline$t_{3}$ & $\left(p_{2}, t_{3}\right),\left(t_{3}, p_{3}\right)$ & $b$ \\
\hline$t_{4}$ & $\left(p_{2}, t_{4}\right),\left(t_{4}, p_{4}\right)$ & $c$ \\
\hline$t_{5}$ & $\left(p_{3}, t_{5}\right),\left(t_{5}, p_{1}\right)$ & $a$ \\
\hline$t_{6}$ & $\left(p_{4}, t_{6}\right),\left(t_{6}, p_{0}\right)$ & $e$ \\
\hline
\end{tabular}

Step 6. The determination of initial marking $M_{0}$

The initial state is $x_{0}=\left\{S_{0}\right\}$ results the initial marking $M_{0}^{T}=[1,0,0,0]$

The graphical representation of the equivalent Petri Net, obtained after the application of the conversion algorithm, is presented in figure 2.

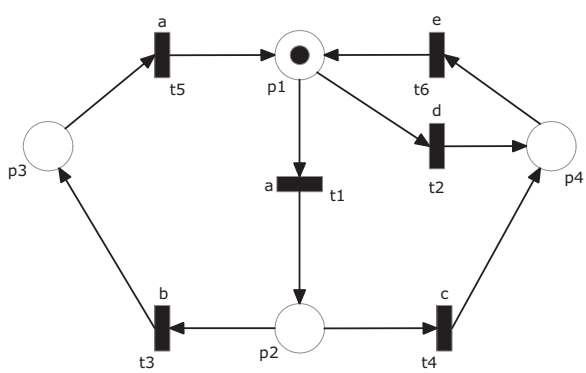

Fig. 2. The equivalent Petri Net

\section{The principles of realization and functioning of the transport systems with accumulation areas}

The industrial transport systems are of different types, depending on the effective mode in which is realized the transport. In this way exists horizontal transport systems or suspended transport systems. Each type of system has its own constructive and functional features, both of them belonging to the TSAA field. In figure 3 is presented a general view of TSAA. 
Fig. 4. Suspended transport system

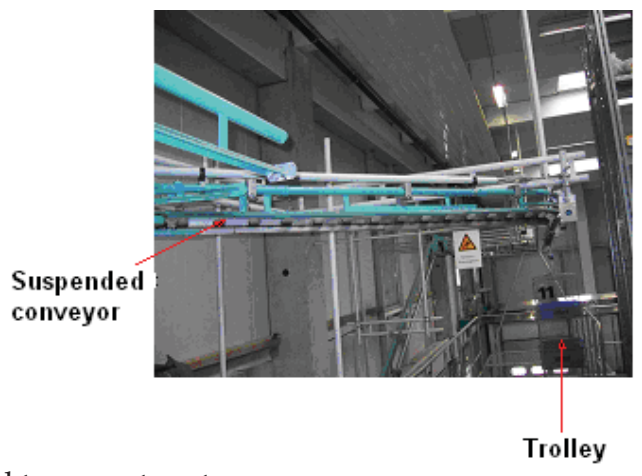

Within the chapter it will be taken into consideration only the suspended transport systems, but the obtained results can be applied also to the horizontal transport systems. Constructive, these are based of the using of brush conveyors as a transport support and have as a main property the assurance of accumulation areas (jams) of the transported elements without being necessary the stopping of conveyor moving motors. The conveyor is moved by an electric motor connected through a mechanical reducer, situated at one of the conveyor extremities. This motor assures the moving of the conveyor with constant speed. The transport element used in the case of these transport systems is the trolley. Each trolley is identified in the system by a unique code bar. This code is used for the determination of the point in which is situated the trolley and for the computing of the route on which this has to follow.

In figure 4 is presented a general picture of the way in which the transport is performed inside a complete automated warehouse of exchange pieces.

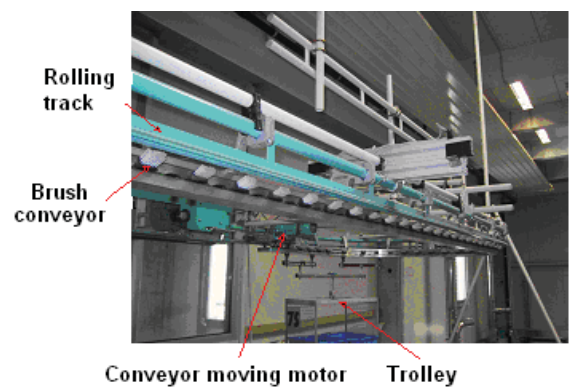

Fig. 5. General picture of a transport system

The main element which assures the stopping of a trolley depending on the used controlling algorithm is the stopper. In figure 5 is presented a stopper used in the case of these systems. 


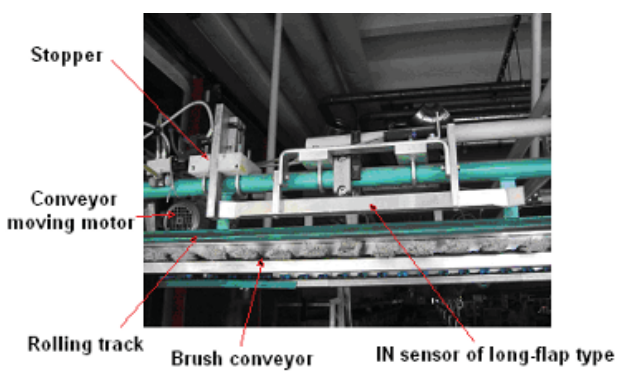

Fig. 6. Stopper and long-flap type sensor

In figure 5 is observed also the sensor which signalize the fact that in the front of the stopper there is a trolley.

\section{Modelling the systems with accumulation areas}

The basic idea in the modelling of such systems is that of assuring the modularization of the elements which makes the transfer of trolleys from one accumulation area into another (Ungureanu-Anghel 2006a)(Ungureanu-Anghel 2006b).

For the modelling of such systems it was established a basic structure (node of type 1 - an input an output), with the help of which can be obtained a general model regardless of its complexity. The observation which has to be made is connected to the fact that further will be no more references connected to the administration of the trolley flux and of their routes in the system, approaching only the issues connected to the modelling of nodes (Ungureanu-Anghel 2006a).

\subsection{Node of type 1 - an input an output}

The basic structure of such a node is presented in figure 6 .

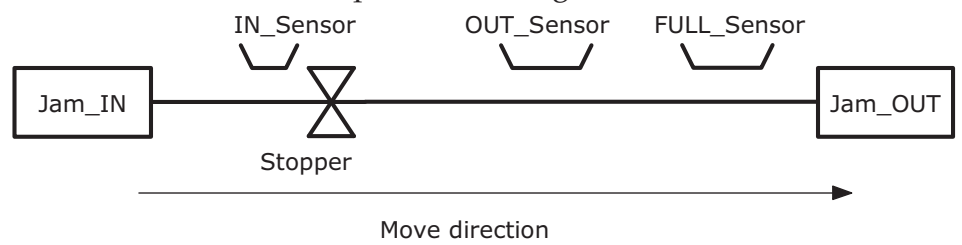

Fig. 7. Node of type 1. An input an output

As can be observed in the mentioned figure, such a node contains a single stopper, having an input and a single output. The sensors used have the following functions:

IN_Sensor The sensor from stopper. With the help of this sensor it is signalized the fact that a trolley is in the front of the stopper.

OUT_Sensor The output sensor. With the help of this sensor is followed the moment in which a trolley has left the stopper area (of the node).

FULL_Sensor Full sensor. With the help of this sensor it is checked the available space in the next jam. 
Jam_IN represents the input jam and Jam_OUT the output jam of the node. The moving motors were not presented because, as it was mentioned, they function continuous.

Before to present the functioning mode of the node of type 1, it is necessary to clearing up the mode of testing of FULL_Sensor.

Since the trolleys are in motion, the signal taken from FULL_Sensor is processed as it is presented in figure 7.

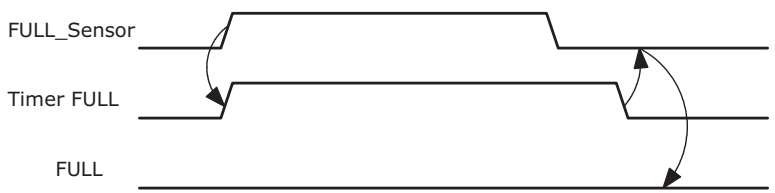

a)

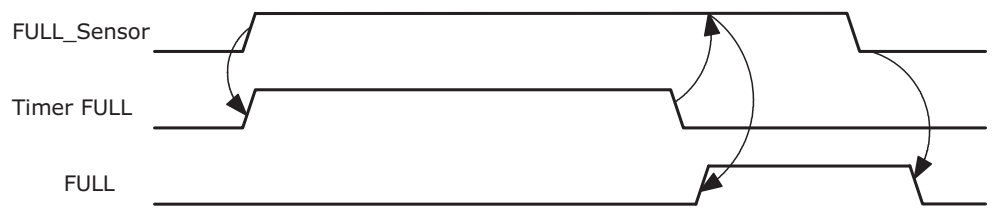

b)

Fig. 8. The mode of processing the signal from FULL_Sensor. a) situation without detection FULL; b) situation of detection FULL

The FULL timer is used for verification with a certain delay of the signal from FULL_Sensor. If at the expiration of the timer the FULL_Sensor is inactive then the event FULL is inactive (figure 7.a), situation in which in Jam_OUT there is still space for at least a trolley. If at the expiration of the FULL timer the FULL_Sensor is active then the event FULL is set as being active, which corresponds to the situation Jam_OUT full. Deactivation of the FULL event is done in the moment in which FULL_Sensor becomes inactive (figure 7.b).

The functioning mode of the node of type 1 starts from the premise that the stopper is closed. A trolley situated in Jam_IN is transported by TEF and at one moment activates the IN_Sensor. The condition for moving the trolley in Jam_OUT area is given by: OUT_Sensor not to be active and FULL not to be active. In other words: in the area after the stopper doesn't have to be a trolley and in the Jam_OUT area has to be at least one free place. The mechanical structure of the node is thus realized so at the activation of OUT_Sensor the trolley has passed entirely by the stopper. The activation of OUT_Sensor has as an effect the closing of the stopper, realizing in this way the separation of two trolleys. A new trolley can be transferred from Jam_IN area in Jam_OUT area only after the OUT_Sensor is inactive, the previous trolley has left the area covered by the OUT_Sensor. For avoiding the uncontrollable situations, for example the stopper is opened and the trolley is jammed and it not touched the OUT_Sensor, are introduced two additional control timers named T1, respectively T2. T1 is used for verification of touching the sensor OUT_Sensor, while T2 for leaving of OUT_Sensor. If one of these timers expires before the touching, respectively the leaving of OUT_Sensor, it means that had appeared an abnormal state of functioning.

The functioning of the node of type 1 without error, described on the base of chronograms is presented in figure 8 . 


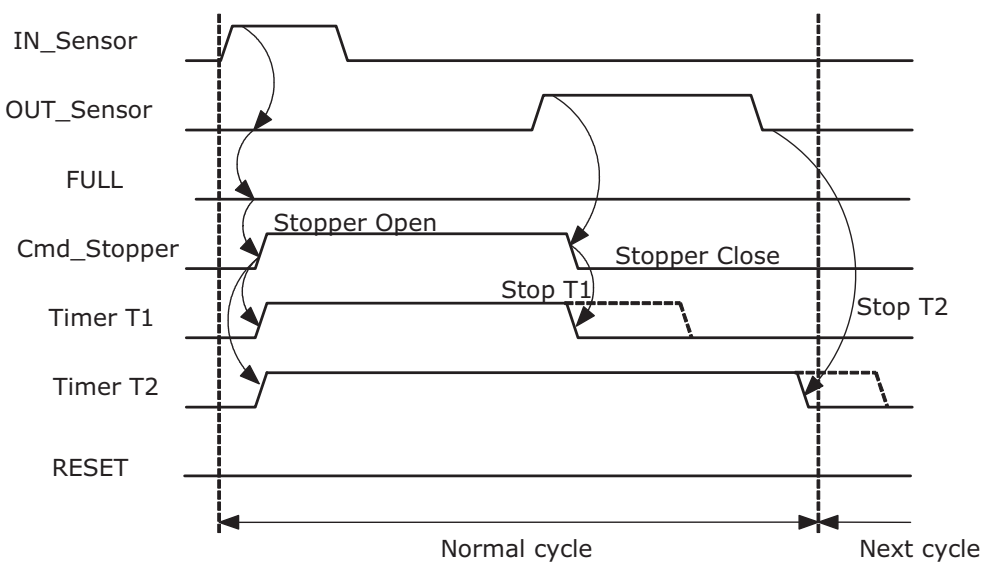

Fig. 9. The functioning chronograms of the node of type 1

The RESET event was introduced for giving the possibility of return in the WAIT state from the error states caused by the expiration of the timers T1 and T2.

The segments with doted line for the timers T1, respectively $\mathrm{T} 2$, represents the normal duration of functioning of the timers.

\subsection{The modelling of the node of type 1 with the help of automata}

The structure of the sequential automata taken into consideration for the modelling of the node of type 1 is presented in figure 9 .

The meanings of the sequential automata states AS_N1 are presented in the table 1.

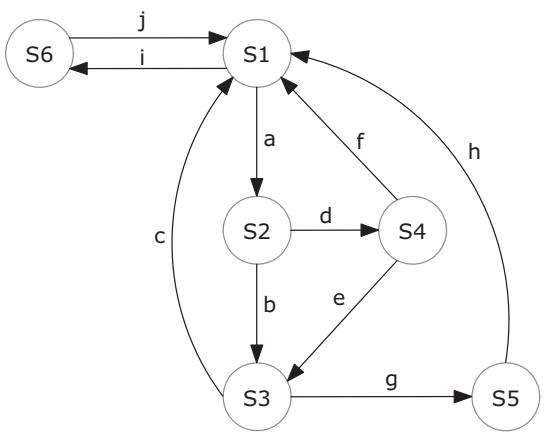

Fig. 10. The structure of the sequential automata corresponding to the node of type 1 


\begin{tabular}{|c|l|}
\hline State & \multicolumn{1}{c|}{ Comment } \\
\hline S1 & $\begin{array}{l}\text { WAIT - The initial state of the system. In this state is waited that a trolley to } \\
\text { reach the stopper (IN_Sensor = 1). Also in this state it is assured the transport of } \\
\text { a trolley from the input sensor from the nod until the IN_Sensor. }\end{array}$ \\
\hline S2 & $\begin{array}{l}\text { OPEN - the state in which the stopper is open, assuring in this way the transfer } \\
\text { of the trolley in the next jam. }\end{array}$ \\
\hline S3 & $\begin{array}{l}\text { CLOSE - state corresponding for closed stopper, but the trolley is still in node } \\
\text { area, not being completely passed to the next jam. }\end{array}$ \\
\hline S4 & $\begin{array}{l}\text { ERROR 1 - error state which is installed if during the moving time of the trolley } \\
\text { it has appeared a critical situation. T1 has expired }\end{array}$ \\
\hline S5 & $\begin{array}{l}\text { ERROR 2 - error state which is installed if during the moving time of the trolley } \\
\text { it has appeared a critical situation. T2 has expired }\end{array}$ \\
\hline S6 & $\begin{array}{l}\text { ERROR 3 - error state which is installed if there is no trolley in IN_Sensor but } \\
\text { OUT_Sensor = 1 }\end{array}$ \\
\hline
\end{tabular}

Table 1. The meanings of automata states AS_N1

The events under which take place the transitions between states are presented in table 2 . The net topology (result obtained with the help of PNT) is shown in figure 10.

Fig. 12. The Petri Net topology validated by PNT

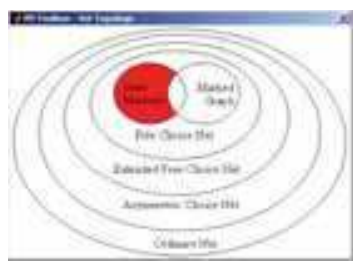

As can be seen, following the transformation of the model of automatic type in the Petri Net model, the net topology obtained is also of type automatic ("state machine"), which allows the analysis of the model of automatic type using the methods from the Petri Nets. 


\begin{tabular}{|c|l|}
\hline Event & \multicolumn{1}{c|}{ Comment } \\
\hline $\mathrm{a}$ & $\begin{array}{l}\text { Event which assures the passing from state S1 in state S2. } \\
\text { Validated (active) based on the condition: IN_Sensor * !OUT_Sensor * !FULL. }\end{array}$ \\
\hline $\mathrm{b}$ & $\begin{array}{l}\text { Event which assures the passing from state S2 in state S3. } \\
\text { Validated (active) based on the condition: OUT_Sensor }=1 .\end{array}$ \\
\hline $\mathrm{c}$ & $\begin{array}{l}\text { Event which assures the passing from state S3 in state S1. } \\
\text { Validated (active) based on the condition: OUT_Sensor }=0 .\end{array}$ \\
\hline $\mathrm{d}$ & $\begin{array}{l}\text { Event which assures the passing from state S2 in state S4. } \\
\text { Validated (active) based on the condition: Timer T1 expirat }\end{array}$ \\
\hline $\mathrm{e}$ & $\begin{array}{l}\text { Event which assures the passing from state S4 in state S3. } \\
\text { Validated (active) based on the condition: OUT_Sensor = 1. }\end{array}$ \\
\hline $\mathrm{f}$ & $\begin{array}{l}\text { Event which assures the passing from state S4 in state S1. } \\
\text { Validated (active) based on the condition: RESET = 1. }\end{array}$ \\
\hline $\mathrm{g}$ & $\begin{array}{l}\text { Event which assures the passing from state S3 in state S5. } \\
\text { Validated (active) based on the condition: Timer T2 expirat. }\end{array}$ \\
\hline $\mathrm{h}$ & $\begin{array}{l}\text { Event which assures the passing from state S5 in state S1. } \\
\text { Validated (active) based on the condition: OUT_Sensor + RESET = 1. }\end{array}$ \\
\hline $\mathrm{i}$ & $\begin{array}{l}\text { Event which assures the passing from state S1 in state S6. } \\
\text { Validated (active) based on the condition: !IN_Sensor * OUT_Sensor. }\end{array}$ \\
\hline
\end{tabular}

Table 2. The meanings of the events corresponding to the automata AS_N1

The corresponding incidence matrices are:

The input incidence matrix:

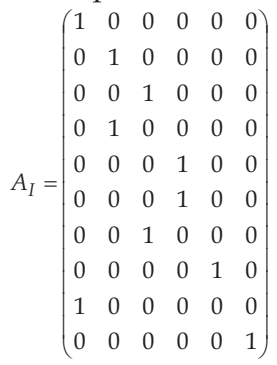

The output incidence matrix:

$$
\text { Incidence matrix: } A=A_{O}-A_{I}=\left(\begin{array}{cccccc}
-1 & 1 & 0 & 0 & 0 & 0 \\
0 & -1 & 1 & 0 & 0 & 0 \\
1 & 0 & -1 & 0 & 0 & 0 \\
0 & -1 & 0 & 1 & 0 & 0 \\
0 & 0 & 1 & -1 & 0 & 0 \\
1 & 0 & 0 & -1 & 0 & 0 \\
0 & 0 & -1 & 0 & 1 & 0 \\
1 & 0 & 0 & 0 & -1 & 0 \\
-1 & 0 & 0 & 0 & 0 & 1 \\
1 & 0 & 0 & 0 & 0 & -1
\end{array}\right)
$$

The corresponding cover tree is presented in figure 11. 


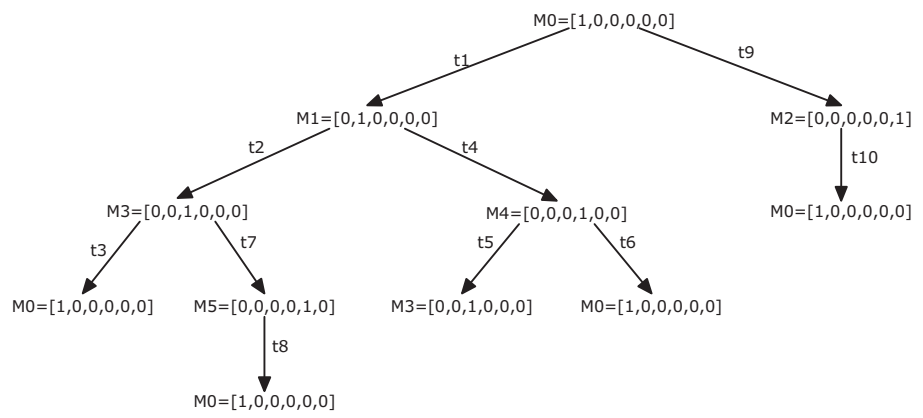

Fig. 13. The cover tree of Petri Net PN_AS_N1

Studying the behaviour properties of the Petri Net PN_AS_N1, based on the cover tree results:

- the net is limited (the symbol $\omega$ does not appear in the cover tree);

- the net is safe (the markings from all the cover tree nodes contains only "0" and "1");

- the net is non-blocking (all transitions have associated arcs in the cover tree);

- the net is accessible (any marking can be reached starting from $M_{0}$ ).

The corresponding cover graph is presented in figure 12.

The resulted structure for the cover graph confirms the fact that the model of Petri Net derived from the model of automatic type corresponding to the node of type 1 is accessible.

Concluding, it can be stated that the chosen model is viable from the behaviour point of view.

The analysis of the Petri Net PN_AS_N1 from structural point of view it is done based on the analysis of the existence of the invariants of type $P$ respectively $T$. To find out the number of invariants $P$, respectively $T$, it was applied the theorem for the determination of the invariants (Pastravanu 1997), which states that if the incidence matrix A (of dimension $n \times m)$ of a Petri Net, has the rank $r$, then: the net posses $m-r$ base invariants $\mathrm{P}$, and each invariant $\mathrm{P}$ of the net $\mathrm{PN}$ can be written as a linear combination of these; the net posses $n-r$ base invariants $\mathrm{T}$, and each invariant $\mathrm{T}$ of the net $\mathrm{PN}$ can be written as a combination of these.

In the considered case, the rank of the matrix $\mathrm{A}$ is: $\operatorname{rank} A=5$.

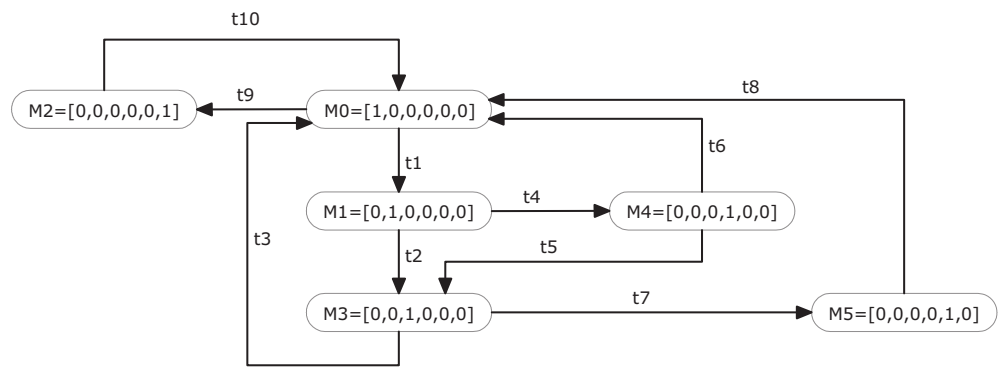

Fig. 14. The cover graph of Petri Net PN_AS_N1

Results that the Petri Net $P N \_A S \_N 1$ is covered by 1 invariant of type $P$. In a similar way, in the case of the invariants of type $T$ results a number of 5 such invariants. The existence of 
the invariants of type P, respectively T leads to the conclusion that the Petri Net PN_AS_N1 is conservative and structural limited, respectively is consistent and repetitive (Pastravanu 1997).

In the end can be stated that the chosen structure for a classic sequential automata corresponding to the node of type 1 is viable, the structure can be implemented, being sure that don't exists conditions of appearance of the blocking or appearance of uncontrollable situations.

\subsection{The modelling of the node „one” input and „m” outputs with the help of automata} The base structure for such a node is presented in figure 13 (Ungureanu\&Prostean 2007) (Ungureanu et al 2008).

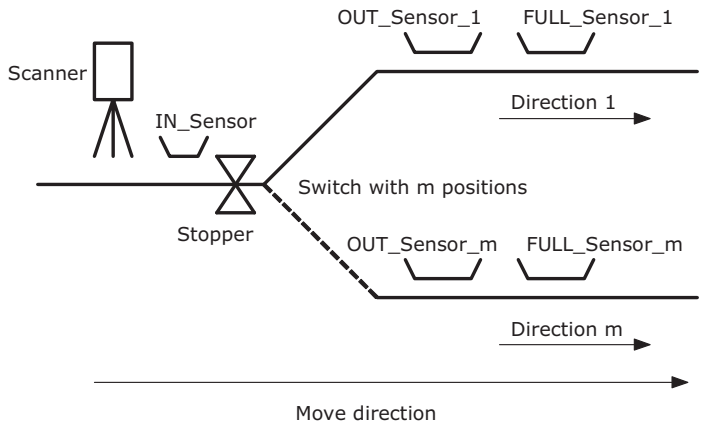

Fig. 15. The base structure of a node with one input and $\mathrm{m}$ outputs

Additional to the aspect of the node of type 1, is observed the appearance of a scanner and of a switch with $m$ positions. With the help of the scanner, by reading the barcode from a trolley and following the list of destinations attached to the trolley, can be determined the direction on which has to be transferred the trolley and is commanded the corresponding switch positioning.

After the switch positioning everything is reduced to a node of type 1.

The position of the switch is not verified through some sensors, because if the switch is not accurate positioned it will appear an abnormal situation of functioning of no touching the corresponding output sensor.

The structure of the sequential automata considered for the modelling of such a node is presented in figure 14 . 


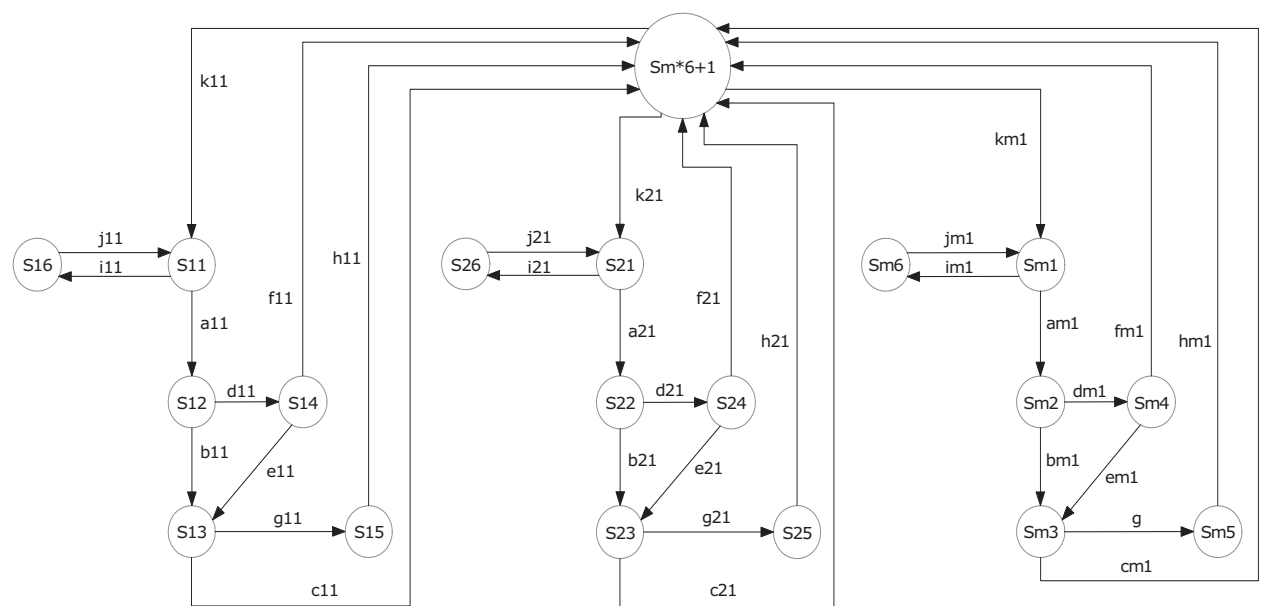

Fig. 16. The structure of the sequential automata corresponding to the node with "one" input and " $m$ " outputs

The sequential automata of the node is realized by the synchronization of $m$ sequential automata AS_N1, one for each input line (stopper).

Mathematically, the automata AS_Nm corresponding to the node with one input and $\mathrm{m}$ outputs is described as follows:

- the multitude of states: $X=\bigcup_{i=1}^{m}\{\operatorname{Si1}, \operatorname{Si2}, \operatorname{Si3}, \operatorname{Si4}, \operatorname{Si5}, \operatorname{Si} 6\} \bigcup\{S(m \cdot 6+1)\}$

- the multitude of events: $\Sigma=\bigcup_{i=1}^{m}\{a i 1, b i 1, c i 1, d i 1, e i 1, f i 1$, gi1, hi1, ii1, ji1, ki1 $\}$

- the multitude of possible events and the transition functions of the states:

$$
\begin{aligned}
& \Gamma(S)=\bigcup_{i=1}^{m} \Gamma(S i) \text { where: } \\
& \Gamma(S i 1)=\{a i\} \\
& \delta(S i 1, a i)=S i 2 \\
& \Gamma(S i 2)=\{b i, d i\} \\
& \delta(S i 2, b i)=S i 3, \\
& \delta(S i 2, d i)=S i 4 \\
& \Gamma(S i 3)=\{c i, f i\} \\
& \delta(S i 3, c i)=S(4 \cdot m+1), \quad \delta(S i 3, f i)=S i 4 \\
& \Gamma(S i 4)=\{e i, g i\} \\
& \delta(S i 4, e i)=S i 3 \\
& \delta(S i 4, g i)=S(4 \cdot m+1) \\
& \Gamma\left(S(4 \cdot n+1)=\bigcup_{i=1}^{m}\{h i\}\right. \\
& \delta(S(4 \cdot m+1), h i)=S i 1
\end{aligned}
$$

- initial state: $x_{0}=S(4 \cdot m+1)$. 
The reasons linked to the transformation of the model of automatic type in the model of Petri Net type, presented in section 2, are valid also in the case of the node with one input and $m$ outputs.

In figure 15 is presented the structure of the Petri Net associated to the sequential automata considered in the case of the node with one input and $m$ outputs.

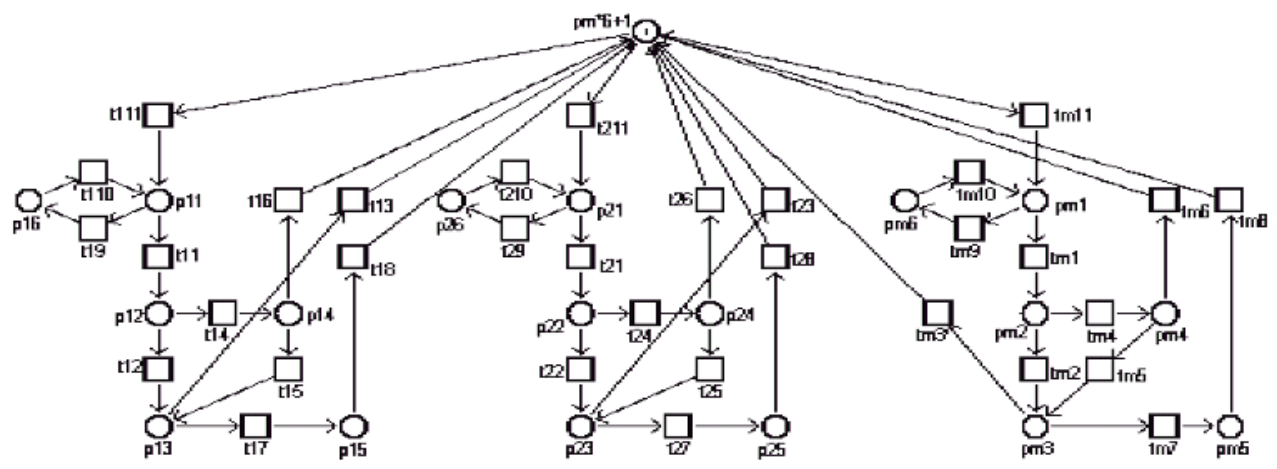

Fig. 17. The structure of the Petri Net associated to the sequential automata corresponding to the node with one input and $\mathrm{m}$ outputs

The net topology validated by PNT is presented in figure 16 .

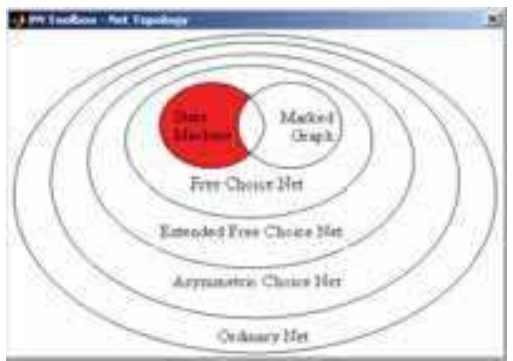

Fig. 18. The equivalent Petri Net topology validated by PNT

The obtained results confirms that after the effectuation of the conversion from the model of automatic type in the model of Petri Net type, the obtained Petri Net topology is also of automatic type („,State machine").

The considered Petri Net is formalized by the quintuple:

$$
P N_{-} A S_{-} N m=\left(P, T, F, W, M_{0}\right)
$$

where:

$$
\text { - } \quad P=\bigcup_{i=1}^{m}\left\{p_{i 1}, p_{i 2}, p_{i 3}, p_{i 4}\right\} \bigcup\left\{p_{4 m+1}\right\}
$$


- $T=\bigcup_{i=1}^{m}\left\{t_{i 1}, t_{i 2}, t_{i 3}, t_{i 4}, t_{i 5}, t_{i 6}, t_{i 7}, t_{i 8}\right\}$

- $F=\bigcup_{i=1}^{m}\left\{\left\{\left(p_{i 1}, t_{i 1}\right),\left(p_{i 2}, t_{i 2}\right),\left(p_{i 2}, t_{i 4}\right),\left(p_{i 3}, t_{i 6}\right),\left(p_{i 3}, t_{i 3}\right),\left(p_{i 4}, t_{i 5}\right),\left(p_{i 4}, t_{i 7}\right),\left(p_{4 m+1}, t_{i 8}\right)\right\} \bigcup\right.$

$$
\left.\left\{\left(t i_{1}, p_{i 2}\right),\left(t_{i 2}, p_{i 3}\right),\left(t_{i 3}, p_{4 m+1}\right),\left(t_{i 4}, p_{i 4}\right),\left(t_{i 5}, p_{i 3}\right),\left(t_{i 6}, p_{i 4}\right),\left(t_{i 7}, p_{4 n+1}\right),\left(t_{i 8}, p_{i 1}\right)\right\}\right\}
$$

$W\left(p_{i 1}, t_{i 1}\right)=1, W\left(p_{i 2}, t_{i 2}\right)=1, W\left(p_{i 2}, t_{i 4}\right)=1, W\left(p_{i 3}, t_{i 6}\right)=1, W\left(p_{i 3}, t_{i 3}\right)=1, W\left(p_{i 4}, t_{i 5}\right)=1$,

- $\quad W\left(p_{i 4}, t_{i 7}\right)=1, W\left(p_{4 m+1}, t_{i 8}\right)=1, W\left(t_{i 1}, p_{i 2}\right)=1, W\left(t_{i 2}, p_{i 3}\right)=1, W\left(t_{i 3}, p_{4 m+1}\right)=1, W\left(t_{i 4}, p_{i 4}\right)=1$, $W\left(t_{i 5}, p_{i 3}\right)=1, W\left(t_{i 6}, p_{i 4}\right)=1, W\left(t_{i 7}, p_{4 m+1}\right)=1, W\left(t_{i 8}, p_{i 1}\right)=1$,

- $\quad M_{0}=[0,0,0,0,0,0,0,0,0,0,0,0, \ldots, 1]^{T}$

The incidence matrices corresponding to the output direction $i$, where the columns are $p_{i 1}$, $p_{i 2}, p_{i 3}, p_{i 4}, p_{i 5}$ and $p_{i 6}$ and the lines: $t_{i 1}, t_{i 2}, t_{i 3}, t_{i 4}, t_{i 5}, t_{i 6}, t_{i 7}, t_{i 8}, t_{i 9}, t_{i 10}$ and $t_{i 11}$ are.

Input incidence matrix:

$$
A_{I i}=\left(\begin{array}{llllll}
1 & 0 & 0 & 0 & 0 & 0 \\
0 & 1 & 0 & 0 & 0 & 0 \\
0 & 0 & 1 & 0 & 0 & 0 \\
0 & 1 & 0 & 0 & 0 & 0 \\
0 & 0 & 0 & 1 & 0 & 0 \\
0 & 0 & 0 & 1 & 0 & 0 \\
0 & 0 & 1 & 0 & 0 & 0 \\
0 & 0 & 0 & 0 & 1 & 0 \\
1 & 0 & 0 & 0 & 0 & 0 \\
0 & 0 & 0 & 0 & 0 & 1 \\
0 & 0 & 0 & 0 & 0 & 0
\end{array}\right)
$$

Output incidence matrix:

$$
A_{O i}=\left(\begin{array}{llllll}
0 & 1 & 0 & 0 & 0 & 0 \\
0 & 0 & 1 & 0 & 0 & 0 \\
0 & 0 & 0 & 0 & 0 & 0 \\
0 & 0 & 0 & 1 & 0 & 0 \\
0 & 0 & 1 & 0 & 0 & 0 \\
0 & 0 & 0 & 0 & 0 & 0 \\
0 & 0 & 0 & 0 & 1 & 0 \\
0 & 0 & 0 & 0 & 0 & 0 \\
0 & 0 & 0 & 0 & 0 & 1 \\
1 & 0 & 0 & 0 & 0 & 0 \\
1 & 0 & 0 & 0 & 0 & 0
\end{array}\right)
$$

Incidence matrix:

$$
A_{i}=A_{O i}-A_{I i}=\left(\begin{array}{cccccc}
-1 & 1 & 0 & 0 & 0 & 0 \\
0 & -1 & 1 & 0 & 0 & 0 \\
0 & 0 & -1 & 0 & 0 & 0 \\
0 & -1 & 0 & 1 & 0 & 0 \\
0 & 0 & 1 & -1 & 0 & 0 \\
0 & 0 & 0 & -1 & 0 & 0 \\
0 & 0 & -1 & 0 & 1 & 0 \\
0 & 0 & 0 & 0 & -1 & 0 \\
-1 & 0 & 0 & 0 & 0 & 1 \\
1 & 0 & 0 & 0 & 0 & -1 \\
1 & 0 & 0 & 0 & 0 & 0
\end{array}\right)
$$


Having the matrices structure for a direction, the matrices corresponding to the node with one input (a stopper) and $m$ outputs are:

The input incidence matrix:

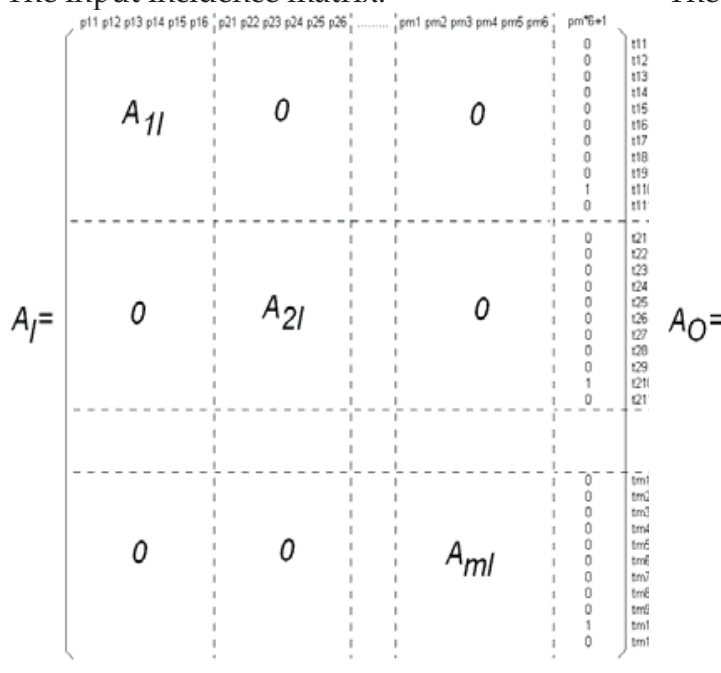

The output incidence matrix:

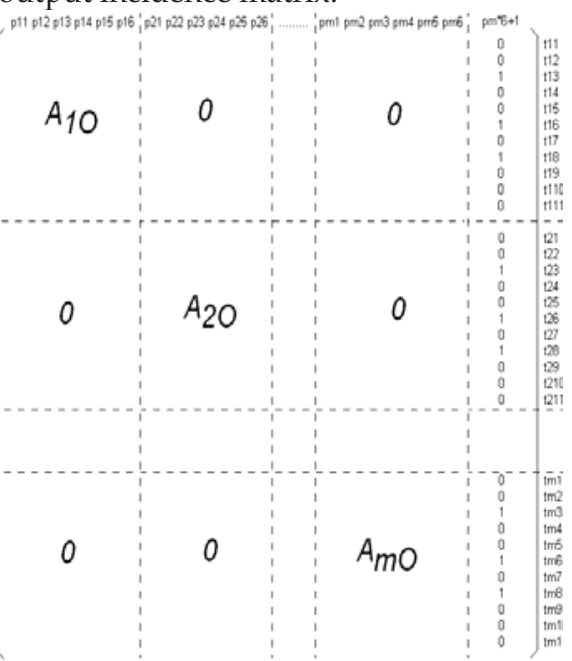

The incidence matrix:

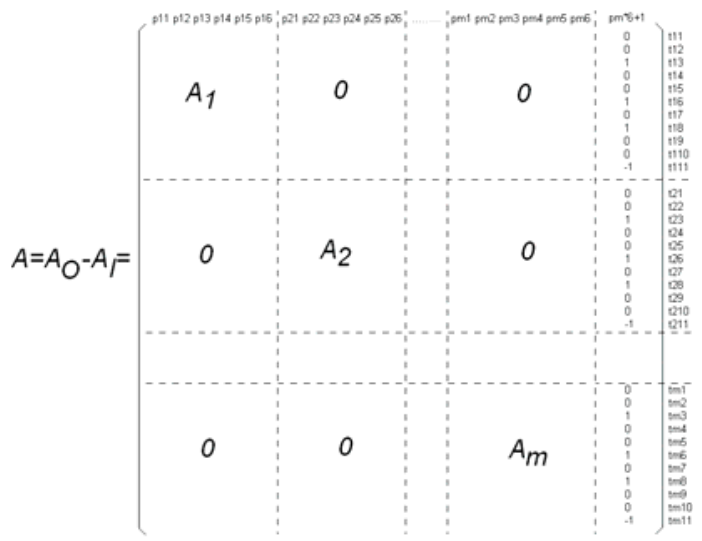

The corresponding cover tree is presented in figure 17. 


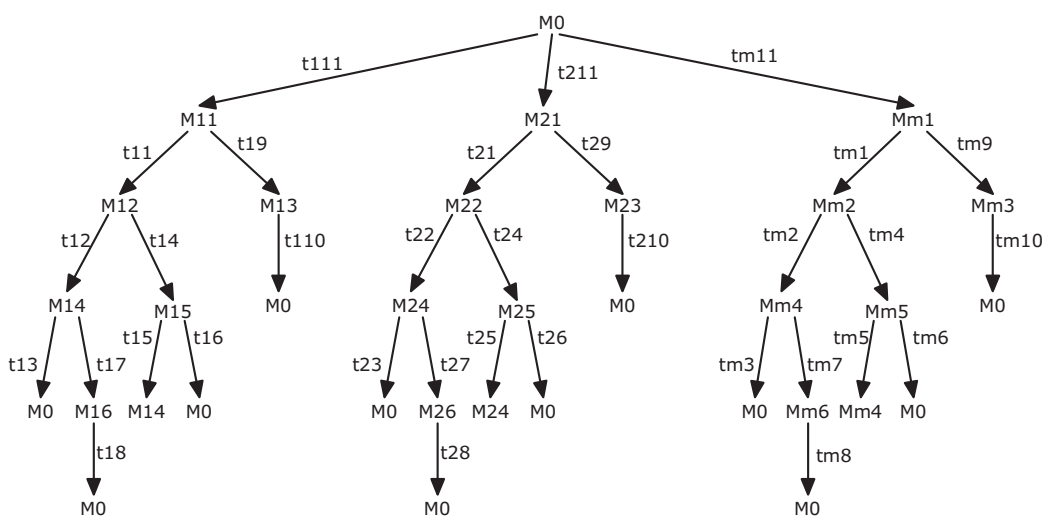

Fig. 19. The cover tree of the Petri Net $P N \_A S \_N n$

Where:

$\mathrm{M} 0=[0,0,0,0,0,0,0,0,0,0,0,0, \ldots, 0,0,0,0,0,0,1]$,

$\mathrm{M} 11=[1,0,0,0,0,0,0,0,0,0,0,0, \ldots, 0,0,0,0,0,0,0]$

$\mathrm{M} 12=[0,1,0,0,0,0,0,0,0,0,0,0, \ldots ., 0,0,0,0,0,0,0]$

$\mathrm{M} 13=[0,0,0,0,0,1,0,0,0,0,0,0, \ldots ., 0,0,0,0,0,0,0]$

M14 $=[0,0,1,0,0,0,0,0,0,0,0,0, \ldots . ., 0,0,0,0,0,0,0]$

M15 $=[0,0,0,1,0,0,0,0,0,0,0,0, \ldots . ., 0,0,0,0,0,0,0]$

M16 $=[0,0,0,0,1,0,0,0,0,0,0,0, \ldots . ., 0,0,0,0,0,0,0]$

M21 $=[0,0,0,0,0,0,1,0,0,0,0,0, \ldots . ., 0,0,0,0,0,0,0]$

M22 $=[0,0,0,0,0,0,0,1,0,0,0,0, \ldots . ., 0,0,0,0,0,0,0]$

M23 $=[0,0,0,0,0,0,0,0,0,0,0,1, \ldots . ., 0,0,0,0,0,0,0]$

M24 $=[0,0,0,0,0,0,0,0,1,0,0,0, \ldots . ., 0,0,0,0,0,0,0]$

M25 $=[0,0,0,0,0,0,0,0,0,1,0,0, \ldots . ., 0,0,0,0,0,0,0]$

M26 $=[0,0,0,0,0,0,0,0,0,0,1,0, \ldots . ., 0,0,0,0,0,0,0]$

$\mathrm{Mm} 1=[1,0,0,0,0,0,0,0,0,0,0,0, \ldots ., 1,0,0,0,0,0,0]$

$\mathrm{Mm} 2=[0,1,0,0,0,0,0,0,0,0,0,0, \ldots . ., 0,1,0,0,0,0,0]$

$\mathrm{Mm} 3=[0,0,0,0,0,1,0,0,0,0,0,0, \ldots . ., 0,0,0,0,0,1,0]$

$\mathrm{Mm} 4=[0,0,1,0,0,0,0,0,0,0,0,0, \ldots . ., 0,0,1,0,0,0,0]$

$\mathrm{Mm} 5=[0,0,0,1,0,0,0,0,0,0,0,0, \ldots . ., 0,0,0,1,0,0,0]$

$\mathrm{Mm} 6=[0,0,0,0,1,0,0,0,0,0,0,0, \ldots . ., 0,0,0,0,1,0,0]$

Studying the behaviour properties of the Petri Net $P N \_A S \_N m$, based on the cover tree results:

- $\quad$ the net is limited (the symbol $\omega$ does not appear in the cover tree);

- the net is safe (the markings from all the cover tree nodes contains only "0" and "1");

- the net is non-blocking (all transitions have associated arcs in the cover tree);

- the net is accessible (any marking can be reached starting from $M_{0}$ ).

Concluding, it can be stated that the chosen model is viable from the behaviour point of view. 
The analysis of the Petri Net PN_AS_Nm from structural point of view it is done based on the analysis of the existence of invariants of type $P$ respectively $T$ (Pastravanu 1997).

The rank of the matrix $\mathrm{A}$ is in this case:

rank $A=n r_{-}$out_node $\cdot \operatorname{rank} N_{1}$

where:

- $\quad n r \_o u t \_n o d e$ - represents the number of the outputs of the node;

- $r a n k N_{1}$ - represents the rank of the incidence matrix corresponding to the node of type $1\left(\operatorname{rankN}_{1}=4\right)$.

The adequate number of invariants $P$ can be calculated with:

$\mathrm{Nr} r_{-}$Inv $v_{-} P=m-\operatorname{rank} A=m-n r_{-}$out_node $\cdot \operatorname{rankN} N_{1}$

and the number of invariants $T$ with:

$\mathrm{Nr} r_{-} I n v_{-} T=n-\operatorname{rank} \mathrm{A}=n-n r_{-}$out_node $\cdot \operatorname{rank} N_{1}$

\subsection{The modelling of the node with $\mathrm{n}$ inputs and $\mathrm{m}$ outputs with the help of automata}

The basic structure of such a node is presented in figure 18 (Ungureanu et al 2008).

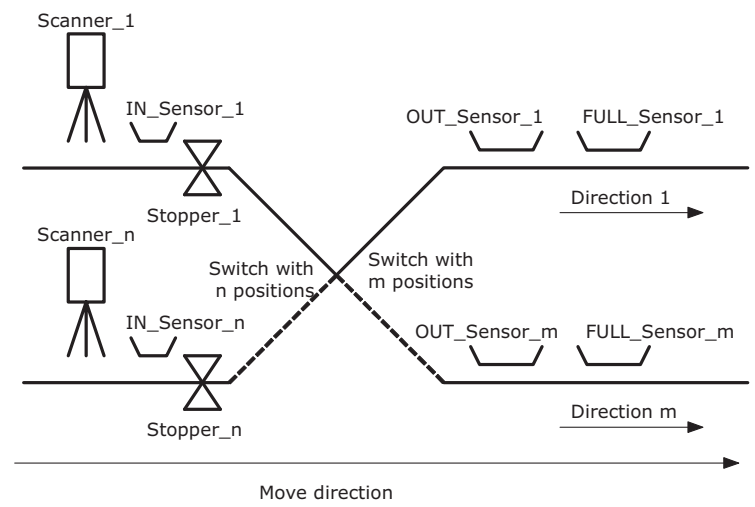

Fig. 20. The principle structure of a node with $\mathrm{n}$ inputs and $\mathrm{m}$ outputs

Towards the node with one input and $m$ outputs, in the case of this node we have $n$ inputs and a switch with $n$ positions.

The condition of functioning for such a node is based on the mutual exclusion, namely a single trolley can be processed at a given moment. The administration of the trolleys from the input sensors can be realized in two ways: based on fixed priorities, respectively on FIFO principle.

Within this chapter is not concerned the mode of administration but strictly the mode of realization of the transfer of trolleys.

After the switch positioning with $n$ positions, can be observed that all is resumed to a node with one input and $m$ outputs.

The structure of the sequential automaton considered for the modelling of a node with $n$ inputs and $m$ outputs is presented in figure 19. 


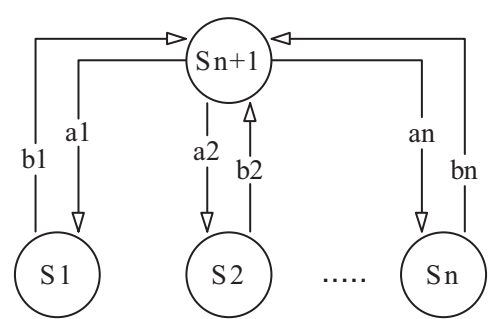

Fig. 21. The structure of the sequential automata corresponding to the node with $n$ inputs and $m$ outputs

In the above figure S1, S2 and Sn represent the automata which are modelling a node with one input and $m$ outputs (are the models of type AS_Nm). The automata synchronization is realized through the additional state $\mathrm{Sn}+1$.

The event ai corresponds to the validation of direction $i$ after the barcode identification (result from the scanning operation). The event bi is generated by the automata $\mathrm{Si}$ at the end of the moving cycle.

The automata AS_Nn-m corresponding to the node with $n$ inputs and $m$ outputs is described as follows:

- the multitude of states:

$$
X=\bigcup_{i=1}^{n}\left\{S_{i}\right\} \cup\left\{S_{n+1}\right\}
$$

- $\quad$ the multitude of events:

$$
\Sigma=\bigcup_{i=1}^{n}\left\{a_{i}, b_{i}\right\}
$$

- the multitude of possible events and the transition functions of the states

$$
\Gamma(S)=\bigcup_{i=1}^{m} \Gamma(S i)
$$

where:

$$
\begin{array}{ll}
\Gamma(S i)=\{b i\} & \delta(S i, b i)=S(n+1) \\
\Gamma(S(n+1))=\{a 1, a 2, \ldots, a n\} & \delta(S(n+1), a i)=S i
\end{array}
$$

- $\quad$ the initial state: $x_{0}=S(n+1)$.

The sub-models used for the modelling of states $S_{i}, i=1, \ldots, n$, are defined identical with the ones presented in the case of the model are AS_Nm.

Applying the transformation algorithm of the automata in Petri Nets results:

- The multitude of positions:

$$
P=\bigcup_{i=1}^{m}\{p i\} \bigcup\{p(n+1)\}
$$


where

$$
p i=\{S i\} \text { and } p(n+1)=\{S(n+1\} ;
$$

- $\quad$ the multitude of transitions:
- For $p i$
$(p i, p(n+1))$
$p(n+1)=\delta(p i, t i 1)$
$t i 1=\{b i\}$
- $\operatorname{For} p(n+1)$
$(p(n+1), p i)$
$p i=\delta(p(n+1), t i 2)$
$t i 2=\{a i\}$

The obtained Petri Net from the conversion operation is presented in figure 20.

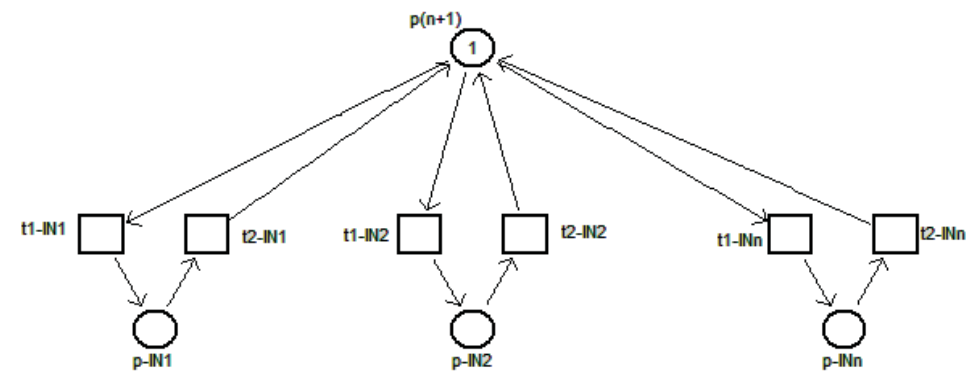

Fig. 22. The Petri Net corresponding to the modelling of the node with $n$ inputs and $m$ outputs derived from the sequential automata $A S \_N m$

The net topology validated by PNT is presented in figure 21 .

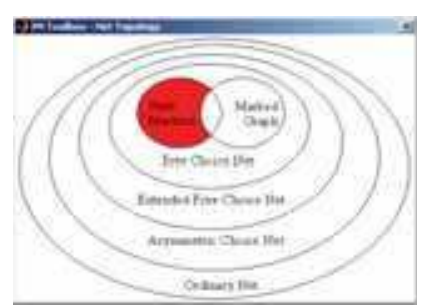

Fig. 23. The equivalent Petri Net topology validated by PNT

The Petri Net considered for the analysis of the sub-model is formalized by the quintuple:

where:

$$
P N_{-} A S_{-} N n-m=\left(P, T, F, W, M_{0}\right)
$$

- $\quad P=\bigcup_{i=1}^{n}\left\{p-I N_{i}\right\} \bigcup\left\{p_{n+1}\right\}$

- $T=\bigcup_{i=1}^{n}\left\{t 1-I N_{i}, t 2-I N_{i}\right\}$ 


$$
\begin{gathered}
F=\left\{\bigcup_{i=1}^{n}\left\{\left\{\left(p-I N_{i}, t 2-I N_{i}\right)\right\} \cup\left\{\left(t 1-I N_{i}, p-I N_{i}\right\}\right\}\right\} U\right. \\
\left.\qquad \bigcup_{i=1}^{n}\left\{\left\{\left(p_{n+1}, t 1-I N_{i}\right)\right\} \cup\left\{\left(t 2-I N_{i}, p_{n+1}\right)\right\}\right\}\right\} \\
\text { - } W\left(p-I N_{i}, t 2-I N_{i}\right)=1, W\left(t 1-I N_{i}, p-I N_{i}\right)=1, \\
W\left(p_{n+1}, t 1-I N_{i}\right)=1, W\left(t 2-I N_{i}, p_{n+1}\right)=1 \\
M_{0}=[0,0, \ldots ., 1]^{T}
\end{gathered}
$$

The incidence matrices are:

The input incidence matrix:

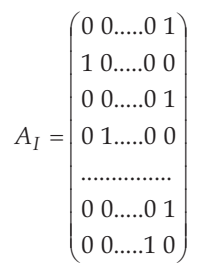

The incidence matrix:

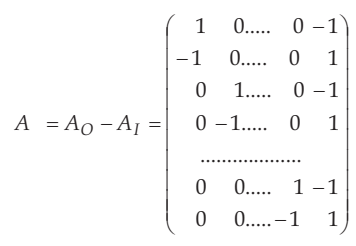

The corresponding cover tree is presented in figure 22 .

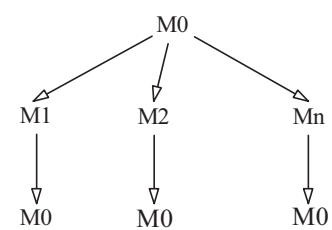

Fig. 24. The cover tree of the Petri Net $P N_{S U B} \_A S \_N n-m$

Where:

$\mathrm{M} 0=(0,0, \ldots ., 0,1) ; \mathrm{M} 1=(1,0, \ldots ., 0,0) ; \mathrm{M} 2=(0,1, \ldots ., 0,0) ; \mathrm{Mn}=(0,0, \ldots ., 1,0) ;$

Studying the behaviour properties of the Petri Net PN_AS_Nn-m, based on the cover tree results:

- the net is limited (the symbol $\omega$ does not appear in the cover tree); 
- the net is safe (the markings from all the cover tree nodes contains only "0" and "1");

- $\quad$ the net is non-blocking (all transitions have associated arcs in the cover tree);

- the net is accessible (any marking can be reached starting from $M_{0}$ ).

The corresponding cover graph is presented in figure 23.

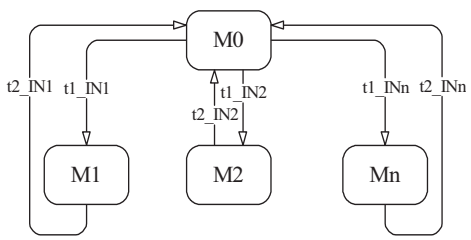

Fig. 25. The cover graph of the Petri Net PN_AS_Nn-m

The obtained structure for the cover tree confirms that the Petri Net, obtained with the help of sub-models corresponding to the sequential automaton of the node with $n$ inputs and $m$ outputs, is accessible.

Concluding, it can be stated that the chosen model is viable from the behaviour point of view.

The analysis of the Petri Net PN_AS_Nn-m from structural point of view is done based on the analysis of the existence of the invariants of type $P$ respectively $T$ (Pastravanu 1997).

The rank of the matrix $\mathrm{A}$ is:

$\operatorname{rank} A=n$

where:

- $n$ - represents the number of node inputs;

The adequate number of invariants $P$ is given by the relation:

$N r_{-}$Inv_ $P=n r_{-}$positions $-\operatorname{rank} A=n+1-n=1$

and the adequate number of invariants $T$ is:

$N r_{-} I n v_{-} T=n r_{-}$transitions $-\operatorname{rank} A=n * 2-n=n$

\section{Conclusions}

Within this chapter it was followed the establishment of a unifying methodology for use of Petri Nets for the structural and behaviour analysis of the automata with direct applications on the transport systems with accumulation areas.

After the presentation of the conversion algorithm of an untimed deterministic automata into a untimed labelled Petri Net, with respecting the condition that the equivalent Petri Net topology to be the state machine, it was proceed to the using of this algorithm for the analysis of the constituent modules of the transport systems with accumulation areas.

The final aim of the chapter was the establishment of a general model of automatic type, for a mechanical structure with $n$ inputs and $m$ outputs, constituent part of a TSAA. To obtain this general model was started from a basic TSAA structure, called node with an input and an output, for which was developed the appropriate model of automatic type. Validation of 
this model was achieved by conversion in model of Petri Net type, its structural and behaviour analysis validating the proposed model of automatic type.

As a simulation environment for the analysis of the equivalent Petri Nets was used PetriNets Toolbox from Matlab.

Having as a base the results obtained for the node with an input and an output, it has passed to the development of a model of automatic type for a node with an input and $\mathrm{m}$ outputs. Validation of the model was done using the same analysis method as in the case of the node with an input and an output.

In the end was elaborated a model of automatic type for a complex structure with $\mathrm{n}$ inputs and $\mathrm{m}$ outputs.

The obtained results following the analysis of this model validated entirely the proposed solution.

Using the general model for a node with $\mathrm{n}$ inputs and $\mathrm{m}$ outputs it can be implemented any types of nodes in a TSAA.

Also, the obtained results lead to the conclusion that the approaching way of the structural and behaviour analysis of untimed deterministic automata, by its conversion in the untimed labelled Petri Net, is viable, with the explanation the equivalent Petri Net topology has to be a state machine. In the future is intended the extending of the areas of applicability of the proposed solution as well as of the results obtained for TSAA for the road and rail transport systems.

\section{References}

C. G. Cassandras, S. Lafortune, „Introduction to Discrete Event Systems”, Kluwer Academic Publishers, 2001, Boston

F. Cassez, O. Roux (2004), "From Petri Nets to Timed Automata", Published by Elsevier Science B.V., 2004

S.Y. Chiang, A. Hu, S. M. Meerkov(2008),"Lean Buffering in Serial Production Lines With Nonidentical Exponential Machines", IEEE Transaction on Automation Science and Engineering, Vol. 5, No. 2, April (2008), pp 298-306

J. Cortadella, M. Kishinevsky, L. Lavago, and A. Yakovlev (1995), “ Synthesizing Petri nets from state-based models", Proc. International Conference Computer-Aided Design (ICCAD), 1995, www.isi.upc.edu/ jordicf/gavina/BIB/CONFERENCE.html

J. Cortadella, M. Kishinevsky, L. Lavagno, A. Yakovlev (1998), “ Deriving Petri Nets from Finite Transition Systems", IEEE Transactions on Computers, Vol. 47, No. 8, August 1998

A. Hellgren, M. Fabian and B. Lennartson. On the Execution of Discrete Event Systems as Sequential Function Charts, Proceedings of the 2001 IEEE Conference on Control Applications, Mexico City, Mexico, September 2001.

M. Ge, Y. Xu, R. Du (2008), “An Intelligent Online Monitoring and Diagnostic System for Manufacturing Automation", IEEE Transaction on Automation Science and Engineering, Vol. 5, No. 1, January 2008, pp 127-139

A. Giua, C. Seatzu (2008), “ Modeling and Supervisory Control of Railway Networks Using Petri Nets", IEEE Transactions on Automation Science and Engineering, Vol. 5, No. 3, July 2008, pp 431-445 
Z. Li, D. Sun, Z. Zhang, J. Song, D. Xiao (2008),"Control Mechanism Analysis of Small-Agent Networks Using a Distinguished Node Model for Urban Traffic Controls", IEEE Transactions on Automation Science and Engineering, Vol. 5 No. 3, July 2008, pp 420-430

Murata T. (1989), “Petri Nets: Properties, Analysis and Applications”, Proceedings IEEE, Vol 77 , pp $541-580$

O. Pastravanu (1997), "Discrete Event Systems. Qualitative techniques in a Petri net framework", Matrix Rom, ISBN 973-9254-61-6, Bucuresti, Romania 1997

A. Polic, K. Jezernik (2008), “Closed-Loop Matrix Based Model of Discrete Event Systems for Machine Logic Control Design”, IEEE Transactions on Industrial Informatics, Vol. 1 No. 1, February 2008, pp 39-46

D. Ungureanu-Anghel (2006a), "Modeling the basic components of automatic transport systems with accumulation areas using sequential automata converted in Petri nets", Sceintific Buletin of "Politehnica" University of Timisoara, Romania, Transactions on Automatic Control and Computer Science, Vol. 51 (65), No. 3, 2006

D. Ungureanu-Anghel (2006b), „Two general untimed Petri net models for the basic components of automatic transport systems with accumulation areas", Sceintific Buletin of "Politehnica" University of Timisoara, Romania, Transactions on Automatic Control and Computer Science, Vol. 51 (65), No. 4, 2006

D. Ungureanu-Anghel, O. Prostean (2007), An Untimed Petri Net Model for an Automatic Transport System with Accumulation Areas, Proceedings of $4^{\text {th }}$ International Symposium on Applied Computational Intelligence and Informatics, SACI 2007, Timisoara, Romania, May 17-18, 2007, pp. 279-284.

D. Ungureanu-Anghel, O. Prostean, D. Ionescu (2008), “General Untimed Sequential Automata Models for the General Components of Automatic Transport Systems with Accumulation Areas", INES 2008 - 12th International Conference on Intelligent Engineering Systems • February 25-29, 2008 Miami, Florida 


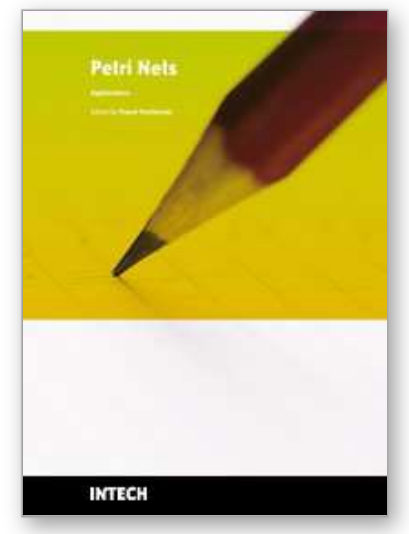

\author{
Petri Nets Applications \\ Edited by Pawel Pawlewski
}

ISBN 978-953-307-047-6

Hard cover, 752 pages

Publisher InTech

Published online 01, February, 2010

Published in print edition February, 2010

Petri Nets are graphical and mathematical tool used in many different science domains. Their characteristic features are the intuitive graphical modeling language and advanced formal analysis method. The concurrence of performed actions is the natural phenomenon due to which Petri Nets are perceived as mathematical tool for modeling concurrent systems. The nets whose model was extended with the time model can be applied in modeling real-time systems. Petri Nets were introduced in the doctoral dissertation by K.A. Petri, titled “"Kommunikation mit Automaten” and published in 1962 by University of Bonn. During more than 40 years of development of this theory, many different classes were formed and the scope of applications was extended. Depending on particular needs, the net definition was changed and adjusted to the considered problem. The unusual "flexibility" of this theory makes it possible to introduce all these modifications. Owing to varied currently known net classes, it is relatively easy to find a proper class for the specific application. The present monograph shows the whole spectrum of Petri Nets applications, from classic applications (to which the theory is specially dedicated) like computer science and control systems, through fault diagnosis, manufacturing, power systems, traffic systems, transport and down to Web applications. At the same time, the publication describes the diversity of investigations performed with use of Petri Nets in science centers all over the world.

\title{
How to reference
}

In order to correctly reference this scholarly work, feel free to copy and paste the following:

Dan Ungureanu-Anghel (2010). Using Petri Nets in the Analysis of Sequential Automata Models with Direct Applications on the Transport Systems with Accumulation Areas, Petri Nets Applications, Pawel Pawlewski (Ed.), ISBN: 978-953-307-047-6, InTech, Available from: http://www.intechopen.com/books/petri-netsapplications/using-petri-nets-in-the-analysis-of-sequential-automata-models-with-direct-applications-on-thetrans

\section{INTECH}

open science | open minds

\section{InTech Europe}

University Campus STeP Ri

Slavka Krautzeka 83/A

51000 Rijeka, Croatia

Phone: +385 (51) 770447

Fax: +385 (51) 686166

\section{InTech China}

Unit 405, Office Block, Hotel Equatorial Shanghai

No.65, Yan An Road (West), Shanghai, 200040, China 中国上海市延安西路65号上海国际贵都大饭店办公楼 405 单元

Phone: +86-21-62489820

Fax: +86-21-62489821 
www.intechopen.com 
(C) 2010 The Author(s). Licensee IntechOpen. This chapter is distributed under the terms of the Creative Commons Attribution-NonCommercial-ShareAlike-3.0 License, which permits use, distribution and reproduction for non-commercial purposes, provided the original is properly cited and derivative works building on this content are distributed under the same license. 